\title{
REVIEW
}

\section{A systematic review on the impact of diabetes mellitus on the ocular surface}

\author{
K Co Shih ${ }^{1,2}$, KS-L Lam ${ }^{2,3,4}$ and L Tong ${ }^{5,6,7,8}$
}

\begin{abstract}
Diabetes mellitus is associated with extensive morbidity and mortality in any human community. It is well understood that the burden of diabetes is attributed to chronic progressive damage in major end-organs, but it is underappreciated that the most superficial and transparent organ affected by diabetes is the cornea. Different corneal components (epithelium, nerves, immune cells and endothelium) underpin specific systemic complications of diabetes. Just as diabetic retinopathy is a marker of more generalized microvascular disease, corneal nerve changes can predict peripheral and autonomic neuropathy, providing a window of opportunity for early treatment. In addition, alterations of immune cells in corneas suggest an inflammatory component in diabetic complications. Furthermore, impaired corneal epithelial wound healing may also imply more widespread disease. The noninvasiveness and improvement in imaging technology facilitates the emergence of new screening tools. Systemic control of diabetes can improve ocular surface health, possibly aided by anti-inflammatory and vasoprotective agents.
\end{abstract}

Nutrition \& Diabetes (2017) 7, e251; doi:10.1038/nutd.2017.4; published online 20 March 2017

\section{INTRODUCTION}

Diabetes mellitus (DM) is a significant public health problem. It is estimated that more than 342 million people worldwide will suffer from DM by 2030 and the total health burden incurred by DM will be driven by the severity of diabetic complications in different organs. The ocular surface, including the superficial and transparent cornea, is known to be involved in diabetes in various ways: this includes common diseases like dry eye and recurrent corneal erosions, previously reviewed elsewhere. ${ }^{1}$ However, new research beyond 2008 has not been systematically reviewed, even after the emergence of fairly recent review articles. ${ }^{2-19}$ This is an important issue to address as new developments such as cellular, molecular biology and animal genetics have advanced considerably in the last few years. Here, we provide a systematic review of the recent literature (published 2009-2015), which enlightens on the role of the ocular surface and cornea in DM (Figure 1) and research on potential treatment strategies.

\section{MATERIALS AND METHODS}

A literature search was conducted on the 5th of January 2016 in the NCBI Entrez Pubmed database and included search terms diabetes and cornea. Articles were limited to journal articles in which the keywords 'cornea' or 'conjunctiva' occur in conjunction with the keyword 'diabetes' in the textword (tw) field of the search. We only examined journal articles published between 1st of January 2009 and 31st of December 2016. The 234 articles identified were then curated by two coauthors (KS and LT) for relevance, via abstract or the full text of the article, and this produced a list of 23 review articles, letters or commentaries (18 reviews) and 110 relevant original articles. For example, articles that involved only the posterior segment of the eye (retina, vitreous) or involving only 'diabetes insipidus' and not 'diabetes mellitus' would be considered irrelevant. A total of 106 were deemed irrelevant.

\section{CORNEA EPITHELIAL DISEASE AND OCULAR SURFACE ABNORMALITIES}

It is known that diabetes is associated with impaired wound healing. This is evident in the corneal epithelium. Diabetic eyes are at increased risk of dry eye, superficial punctate keratitis, recurrent corneal erosion syndrome and persistent epithelial defects. ${ }^{20,21}$ As the corneal epithelium is the first layer of the eye, it is constantly subjected to wear and tear and it needs to be constantly regenerated. Any process that affects wound healing or the speed of epithelial regeneration will have physiological impact and increases morbidity including ocular pain and redness. ${ }^{22-25}$

Recently a human study conducted in a hospital showed for the first time that tear levels of type 1 and 2 diabetic individuals had significantly higher insulin-like growth factor binding protein (IGFBP3) compared with age-matched normal adults. IGFBP3 is a multifunctional protein that is known to play a negative regulatory role in IGF signaling by binding and sequestrating it, competing with its cellular receptor IGFR-1. In the wider context, IGFBP3 has been known to regulate insulin resistance, apoptosis as well as oxidative damage. The processes regulating the secretion of IGFBP3 from corneal epithelial tissue is not known, but in experiments with immortalized human corneal epithelial cells, it was found that high levels of glucose in the culture medium can induce the production of IGFBP3, suggesting that the

\footnotetext{
${ }^{1}$ Department of Ophthalmology, Li Ka Shing Faculty of Medicine, The University of Hong Kong, Hong Kong SAR, China; ${ }^{2}$ Research Center of Heart, Brain, Hormone and Healthy Aging, The University of Hong Kong, Hong Kong; ${ }^{3}$ Department of Medicine, The University of Hong Kong, Hong Kong; ${ }^{4}$ State Key Laboratory of Pharmaceutical Biotechnology, The University of Hong Kong, Hong Kong; ${ }^{5}$ Singapore Eye Research Institute, National Eye Centre, Singapore; ${ }^{6}$ Yong Loo Lin School of Medicine, National University of Singapore, Singapore; ${ }^{7}$ Department of Ophthalmology, Singapore National Eye Center, Singapore and ${ }^{8}$ Department of Ophthalmology, Duke-NUS Medical School, Singapore. Correspondence: Dr L Tong, Department of Ophthalmology, Singapore Eye Research Institute, 11 Third Hospital Avenue, Singapore 168751, Singapore.

E-mail: louis.tong.h.t@snec.com.sg

Received 5 October 2016; revised 10 November 2016; accepted 14 November 2016
} 


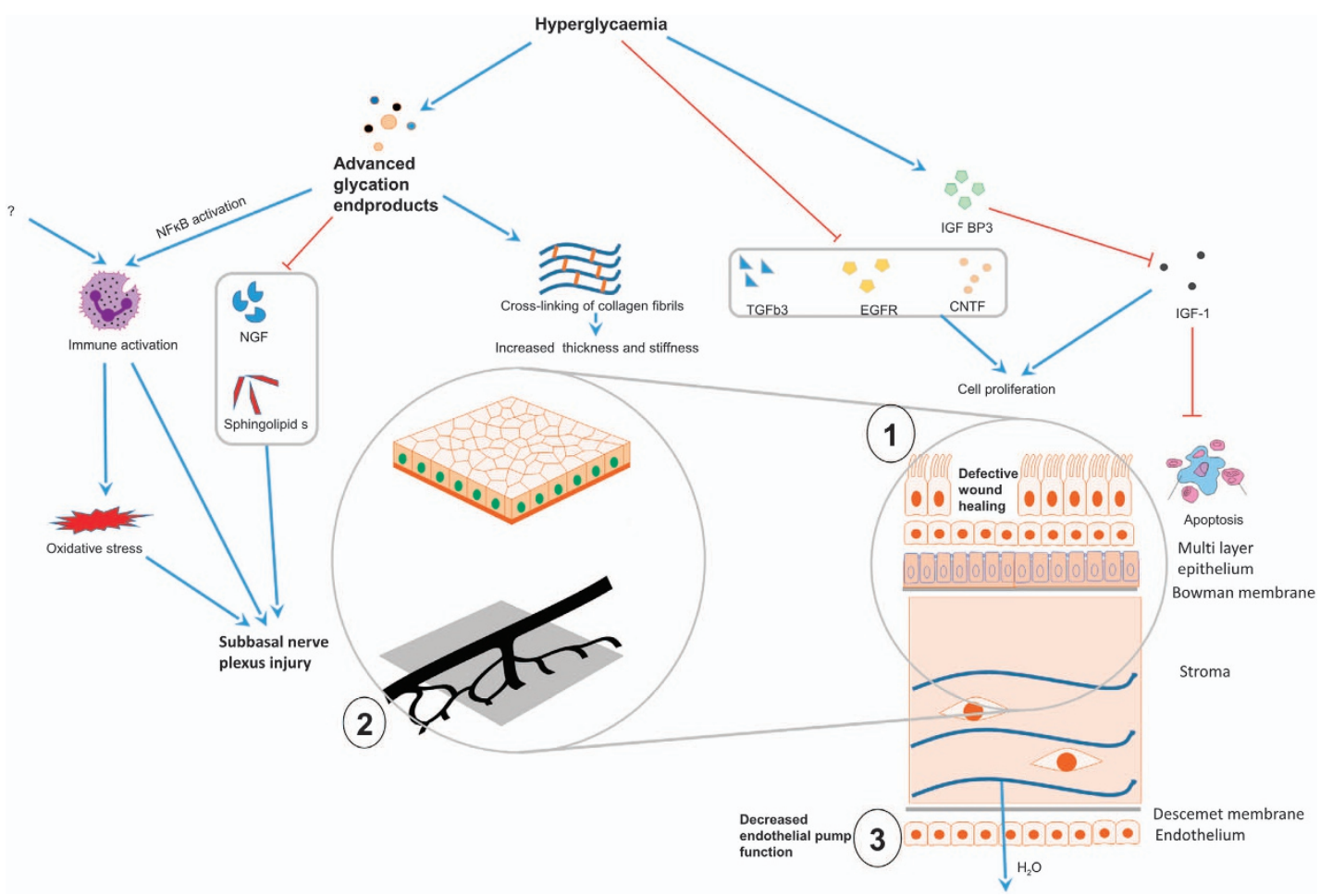

Figure 1. Schematic showing pathogenesis of corneal disease in diabetes mellitus. Hyperglycemia and formation of advanced glycation end products have distinct effects on different parts of the cornea, resulting in three principal types of tissue dysfunction with physiological effects that can be measured. (1) Defective wound healing in the corneal epithelium, (2) abnormalities of sub-basal nerves and (3) loss of corneal endothelial pump function. (1) Raised blood glucose promotes IGFBP3 release, which in turn competitively inhibits IGF-1, whereas TGFb3, EGFR, CNTF are suppressed in hyperglycemic states. The consequential reduction in epithelial cell proliferation and increased apoptosis impacts on epithelial wound healing. (2) Neuronal damage is a key defect in diabetes mellitus. Prolonged hyperglycemia results in the accumulation of advanced glycation end products which promotes inflammation and oxidative stress. NGF and sphingolipids are key to neuronal health and myelin formation, but their production are inhibited in hyperglycemic states. (3) Prolonged hyperglycemia also results in endothelial cell loss and impairment in pump function. Apart from these processes, the swelling of the corneal stroma (the main bulk of the cornea) may be due to loss of epithelial barrier, crosslinking of stromal collagen and matrix, and loss of the endothelial pump. CNTF, ciliary neurotrophic factor; EGFR, epithelial growth factor receptor; IGF-1, insulin-like growth factor 1; NF-kB, nuclear factor kappa-light-chainenhancer of activated B cells transcription factor; NGF, nerve growth factor; TGFb3, transforming growth factor beta-3. Solid blue arrowsactivation/promotion, red stop arrows-inhibition or negative regulation.

hyperglycemia in patients may be the cause of the IGFBP3 upregulation. This paper did not examine other potential sources of IGFBP3 such as lacrimal glands and immune cells. In addition, the clinical examination results of the corneal epithelium of the participants such as presence of epitheliopathy were not reported. ${ }^{26}$

Two studies with $\mathrm{C} 57 \mathrm{db} / \mathrm{db}$ mice $\mathrm{e}^{27,28}$ and four studies involving rats ${ }^{24,29-31}$ showed that hyperglycemia induced detrimental effects on the cornea epithelium-basement membrane complex. In these studies, decreases in corneal epithelial function were documented by an increase in corneal thickness, and structural changes were examined by electron microscopy. ${ }^{24,29,30}$ Since the normal corneal epithelium plays an important barrier function in excluding water from entering the stroma, a reduction in the barrier function will manifest as edema and swelling of the normally relatively dehydrated stroma. The component of the epithelium forming the barrier is largely sub-served by tight junctional complexes between cornea epithelial cells, visualized as electron dense structures. Loss or disruption of these tight junction structures or loss of basal corneal epithelial cells on imaging would explain loss of epithelial function. The loss of epithelial function can affect vision because the onset of edema causes cornea opacification and will directly affect transmission of light through the cornea. ${ }^{32}$
Use of diabetic animals has both advantages and constraints. The obvious advantage is the ability to obtain ocular tissue, but the main advantage of using these models is the possibility of examining changes before and after induction of diabetes. Such changes are almost impossible to evaluate in human patients as they would not have come to the attention of health professionals prior to the development of diabetes. The major limitation of animal models is that the induction of DM occurs fairly rapidly using one intervention compared with the more chronic, multifactorial DM in humans, and therefore the disturbance may not be translatable to human disease. Induction of diabetes may be via injection of streptozotocin in Sprague Dawley (SD) rats, or in some cases, rats may be naturally diabetic such as Otsuka Long-Evans Tokushima fatty (OLETF) rats. Streptozotocin destroys beta islet cells in the pancreas of the animals, with reduction of insulin secretion and consequent hyperglycemia. The hyperglycemiarelated effects as well as the oxidative stress associated with ingestion of fat and ethanol in OLEFT rats then induce systemic organ damage. ${ }^{22}$

One of the molecular changes detected in animal eyes is the measurement of levels of advanced glycation end products (AGE). ${ }^{30}$ This is an important pathological outcome as it is considered to be the mediator for all chronic DM complications including macrovascular and microvascular complications such as diabetic retinopathy in the eye. The accumulation of AGE in the 
cornea epithelium-basement membrane shifts local cell signaling towards pro-apoptotic and antiproliferative pathways, as well as increases oxidative stress and inflammation. A typical way of measuring oxidative stress in the ocular surface tissue is the quantification of the level of the oxidized nucleotide 8hydroxydeoxyguanosine. ${ }^{30}$ A separate study found the gammaglutamyl transferase level in the tear to be reduced in 14 type 1 and 2 DM participants compared with 14 control participants. However, in cornea buttons of cadavers, the tissue levels of the enzyme were lower in type $1 \mathrm{DM}$ than in type $2 \mathrm{DM}$ and controls. While these are interesting results in view of the possible role of the transferase in oxidative stress, more studies are required to determine the mechanistic significance. ${ }^{33}$

As DM is a chronic disease, it is important to differentiate molecular changes that induce the disease as opposed to molecules that mediate secondary complications. Distinct ultrastructural tissue alterations may occur in pre-diabetic eyes as well as in established DM. ${ }^{29}$ Here in vitro studies ${ }^{23,28}$ and animal models $^{30}$ are useful to chart the temporal changes as the corneal levels of epithelial growth factor receptor, ciliary neurotrophic factor and nuclear factor kappa B may be determined at different stages of disease. TGFb3, epithelial growth factor receptor and ciliary neurotrophic factor have already been found to promote corneal epithelial wound healing in studies on wound healing and found to be reduced in corneas of diabetic animals. The nuclear factor kappa B on the other hand is an important transcription factor that affects inflammation and cell development found to be increased in corneas of diabetic animals. ${ }^{34-36}$

\section{CORNEA NEUROPATHY}

The sensory innervation of the cornea is a major determinant of epithelial health and healing capacity. ${ }^{37}$ This may be mediated by secretion of substance $\mathrm{P}$ by the nerves and binding to neurokinin1 receptor on the epithelial cells. ${ }^{38}$ Corneal nerves are branches of the ophthalmic nerve, which is a branch of the trigeminal cranial nerve. They perforate the corneal stroma at the medial and lateral positions and branch into neurites that eventually sprout nerve endings anteriorly into the corneal epithelium. ${ }^{3}$

The cornea is the most densely innervated structure in humans, with nerve fibers playing an important neurotrophic role in the development of a healthy corneal surface. Loss of neurotrophic function may result in a non-healing or persistent cornea epithelial defect or neurotrophic ulcer. This has associated cornea edema and disturbance of visual function and is an important cause of morbidity in cornea clinics. ${ }^{39}$

Unlike other areas of the body, corneal nerves can be easily visualized in the transparent anterior corneal stroma by modern imaging techniques in clinical scenarios without invasive biopsy procedures. Essentially the in vivo findings have been confirmed by cadaveric ex vivo studies. ${ }^{40}$

\section{Advances in confocal imaging techniques}

The most important advance in the last few years is the use of modern scanning laser ophthalmoscopy. The most common form of this in vivo confocal microscopy is the Heidelberg Retinal Tomography (Heidelberg, Germany), which is performed in conjunction with a corneal modular lens. ${ }^{10,11,14,41}$ Images acquired are processed by imaging software for indices of nerve fiber density, nerve fiber length, nerve branch density and nerve tortuosity ${ }^{42}$ in the sub-basal nerve plexus because changes in this layer are more relevant in DM than in intrastromal nerves. One research group used NeuronJ, a plug-in for the NIH freeware Image $\mathrm{J}^{43}$ whereas the other group used proprietary ACModule and CCModule software developed in the University of Manchester.
Specific nerve indices may have been found to be useful in a particular region of the cornea for some clinical scenarios. Analysis of the sub-basal nerve plexus ${ }^{44-49}$ can be performed in two regions of the cornea: central cornea and the inferior whorl. ${ }^{50}$ For example, it has also been reported that the nerve fiber density at the inferior whorl region is more sensitive to early nerve fiber damage than the central corneal region, in DM patients before development of peripheral neuropathy. ${ }^{51}$

Scans can be evaluated manually (CCModule), in semiautomated fashion (NeuronJ) or in a fully automated (ACCModule) technique. ${ }^{52,53}$ All three methods were reported to have high repeatability, which can be further improved with experience but not by increasing magnification. ${ }^{54-60}$ The speed of image analysis can be improved with use of automated quantification techniques

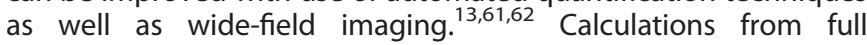
automation are well correlated to those by manual methods, and so may be useful in communities without a manual evaluator. 5

\section{Clinical studies}

It is well known for many years that corneal nerve density is reduced in type $1 \mathrm{DM}^{3}$ Recently both types of DM have been associated with reduction of corneal nerve density and other corneal nerve abnormalities (Table 1). ${ }^{19,45,47,63-65}$

Reduction in corneal nerve fiber density is a characteristic manifestation of diabetic corneal neuropathy, with demonstrated progression over time, in a 4 year cohort study of DM participants from two countries (Australia and UK). ${ }^{66}$

An interesting question would be whether good glycemic control restores the corneal nerve innervation and dysfunction? Two clinical cohort studies have concluded that once DM (type 1 and type 2) was established, good glycemic control was able to improve but not completely reverse corneal neuropathy. ${ }^{67,68}$

Corneal nerve parameters have been found to correlate to diabetic peripheral neuropathy and autonomic neuropathy (Table 2). ${ }^{43,46,48,49,66,69-73}$ Diabetic peripheral neuropathy, a common complication in up to $54 \%$ of diabetic population, is a significant cause of morbidity and poor quality of life in diabetic patients. As such, early detection of high-risk patients can preempt the course of the disease with measures such as better footcare to improve healthcare outcomes.

Conventional clinical diagnosis of diabetic peripheral neuropathy includes clinical assessment and nerve conduction studies. However, these tests detect large fiber deficits, rather than the small unmyelinated $C$ and thinly myelinated $A \delta$-nerve fibers which are affected earlier in the course of the disease. ${ }^{15,74-76}$ The higher density and the preponderance of small nerve fibers in the cornea may explain why corneal nerve fiber changes can be detected before awareness of diabetic peripheral neuropathy in the lower limbs. $6,16,17,45,77$ Decreases in nerve fiber length in sub-basal nerve plexus have also been found to be associated with subclinical diabetic autonomic neuropathy which may be life-threatening, including cardiovascular complications such as arrhythmias or sudden cardiac deaths. ${ }^{46,71,72}$ The vagal function is used as a measure of autonomic neurological function, assessed by the change of heart rate in response to breathing and posture.

\section{Mechanisms of corneal neuropathy}

Broadly, peripheral neuropathies are considered microvascular DM complications as a result of nerve ischemia. The conventional view is that AGE initiates damage to the pericytes and endothelium of capillaries and reduces microvascular supply to Schwann cells or neurons. This consequently decreases neuronal function. If the status of corneal nerves reflects peripheral nerve status, understanding the mechanism of the corneal neuropathy is vital. ${ }^{3}$

Microvascular abnormalities occur in the retina as well as in the cornea. Reduction of corneal nerve fiber density or length have 
Table 1. Studies comparing corneal nerve parameters in diabetic subtypes

\begin{tabular}{|c|c|c|c|c|c|c|c|}
\hline Source & Country & Groups $^{\mathrm{a}}$ & Sample size & Method & Parameter (mean) & Outcomes ${ }^{c}$ & Associations \\
\hline $\begin{array}{l}\text { Messmer et al. } \\
(2010)^{45}\end{array}$ & Germany & $\begin{array}{l}\text { Type I and II } \\
\text { DM vs } \\
\text { controls }\end{array}$ & $13 / 54 / 24$ & $\begin{array}{l}\text { HRT II } \\
\text { Image J } \\
\text { Esthesiometer }\end{array}$ & $\begin{array}{l}\left.\text { NFD (no. } \mathrm{mm}^{-2}\right) \\
\text { NFL }\left(\mathrm{mm} \mathrm{mm}^{-2}\right) \\
\left.\text { NBD (no. } \mathrm{mm}^{-2}\right) \\
\text { NT }\end{array}$ & $\begin{array}{l}\mathrm{DM} 1 / \mathrm{DM} 2 / \mathrm{C}: \\
16.9 / 16.1 / 23.3 \\
9.7 / 10.7 / 16.1 \\
1.5 / 1.6 / 1.4\end{array}$ & $\begin{array}{l}\text { Increasing severity of nerve fiber } \\
\text { parameters with higher stages of } \\
\text { diabetic retinopathy, history of } \\
\text { nephropathy, peripheral neuropathy, } \\
\text { and decreased corneal sensation } \\
\text { predictive of abnormal CCM } \\
\text { parameters, first paper to demonstrate } \\
\text { abnormal CCM parameters in patients } \\
\text { with normal corneal and vibration } \\
\text { sensation }\end{array}$ \\
\hline $\begin{array}{l}\text { Ischibashi et al. } \\
(2012)^{63}\end{array}$ & Japan & $\begin{array}{l}\text { Type I DM vs } \\
\text { controls }\end{array}$ & $38 / 38$ & $\begin{array}{l}\text { HRT III } \\
\text { Image J }\end{array}$ & $\begin{array}{l}\left.\text { NFD (no. } \mathrm{mm}^{-2}\right) \\
\text { NFL }\left(\mathrm{mm} \mathrm{mm}^{-2}\right) \\
\text { NT } \\
\text { Beading }(\mathrm{mm})\end{array}$ & $\begin{array}{l}\mathrm{DM} 1 / \mathrm{C}: \\
25.32 / 36.62 \\
9.80 / 13.65 \\
3.13 / 1.74 \\
22.38 / 30.44\end{array}$ & $\begin{array}{l}\mathrm{HbA} 1 \mathrm{c} \text { level and blood pressure were } \\
\text { an independent negative predictors of } \\
\mathrm{NFL} \text { and NFD }\end{array}$ \\
\hline $\begin{array}{l}\text { Nitoda et al. } \\
(2012)^{47}\end{array}$ & Greece & $\begin{array}{l}\text { Type II DM } \\
\text { (noDR/ } \\
\text { NPDR/NPDR/ } \\
\text { PDR) vs } \\
\text { controls }\end{array}$ & $46 / 47 / 46 / 47$ & $\begin{array}{l}\text { HRT II, } \\
\text { MATLAB }\end{array}$ & $\begin{array}{l}\left.\text { NFD (no. } \mathrm{mm}^{-2}\right) \\
\text { NBD }\left(\text { no. } \mathrm{mm}^{-2}\right) \\
\text { NFL }\left(\mathrm{mm} \mathrm{mm}^{-2}\right) \\
\text { NT }\end{array}$ & $\begin{array}{l}\text { DM2 noDR/NPDR/ } \\
\text { PDR/C: } \\
\text { 27.4/23.7/18.8/31.3 } \\
39.9 / 30.6 / 25 / 45.1 \\
14.8 / 12.3 / 10.4 / 16.6 \\
1.8 / 1.9 / 1.9 / 1.7\end{array}$ & $\begin{array}{l}\text { Positive correlation between corneal } \\
\text { neuropathy and peripheral neuropathy }\end{array}$ \\
\hline $\begin{array}{l}\text { Zhivov et al. } \\
(2013)^{64}\end{array}$ & Germany & $\begin{array}{l}\text { DM vs } \\
\text { controls }\end{array}$ & $36 / 20$ & $\begin{array}{l}\text { HRT II } \\
\text { GIMP } \\
\text { Non-invasive } \\
\text { esthesiometer }\end{array}$ & $\begin{array}{l}\text { NFD }\left(\mathrm{mm} \mathrm{mm}^{-2}\right) \\
\text { NFL }\left(\mathrm{mm} \mathrm{mm}^{-2}\right) \\
\text { NBD }\left(\text { no. } \mathrm{mm}^{-2}\right)\end{array}$ & $\begin{array}{l}\text { DM/C: } \\
0.006 / 0.020 \\
6.22 / 19.99 \\
25.3 / 141.9\end{array}$ & $\begin{array}{l}\text { No difference in CCM parameters } \\
\text { between patients with or without } \\
\text { diabetic retinopathy, corneal sensation } \\
\text { was significantly lower in the diabetic } \\
\text { group than in controls }\end{array}$ \\
\hline $\begin{array}{l}\text { Wang et al. } \\
(2014)^{19}\end{array}$ & China & $\begin{array}{l}\text { Type II DM } \\
\text { vs controls }\end{array}$ & $45 / 50$ & - & $\begin{array}{l}\mathrm{NFL}\left(\mathrm{mm} \mathrm{mm}^{-2}\right) \\
\left.\text { NBD (no. } \mathrm{mm}^{-2}\right) \\
\text { NT }\end{array}$ & $\begin{array}{l}\mathrm{DM} 2 / \mathrm{C}: \\
11 / 13 \\
47 / 623.2 / 2.8\end{array}$ & $\begin{array}{l}\text { Pain severity of diabetic peripheral } \\
\text { neuropathy showed negative } \\
\text { correlation with NFL and NBD, positive } \\
\text { correlation with NT }\end{array}$ \\
\hline $\begin{array}{l}\text { Ziegler et al. } \\
(2014)^{65}\end{array}$ & Germany & $\begin{array}{l}\text { Type II DM } \\
\text { vs controls }\end{array}$ & $86 / 48$ & $\begin{array}{l}\text { HRT ॥ } \\
\text { Esthesiometer }\end{array}$ & $\begin{array}{l}\text { NFL }\left(\mathrm{mm} \mathrm{mm}^{-2}\right) \\
\left.\text { NFD (no. } \mathrm{mm}^{-2}\right) \\
\left.\text { NBD (no. } \mathrm{mm}^{-2}\right)\end{array}$ & $\begin{array}{l}\text { DM2/C: } \\
19.7 / 24.9 \\
299.2 / 397.3 \\
165.2 / 226.7\end{array}$ & \\
\hline
\end{tabular}

Abbreviations: ${ }^{\mathrm{a} D M}$, diabetes mellitus; DR, diabetic retinopathy; NPDF, non-proliferative diabetic retinopathy; PDR, proliferative diabetic retinopathy. ${ }^{\mathrm{b}} \mathrm{NBD}$, nerve branch density; NFD, nerve fiber density; NFL, nerve fiber length; NT, nerve tortuosity. ${ }^{\circ} \mathrm{C}$, control; DM1, type 1 diabetes mellitus; DM2, type 2 diabetes melliltus.

been shown to predict the development of diabetic retinopathy as well as sight-threatening retinopathy. ${ }^{45,47,78}$

The formation of AGE may not be the initial trigger for pericyte damage or neuronal loss. Inflammation may play a role as high concentrations of Langerhans cells and dendritic cells, the main antigen-presenting cells in the ocular surface, aggregate around corneal nerve fibers early in the disease process. ${ }^{79,80}$ In addition, levels of neurotrophic factors may be reduced in DM, for example, reduction in serum nerve growth factor and lipids such as sphingolipids have been detected in diabetic eyes compared with controls. $^{81,82}$

The cause or extent of immune dysfunction, if any, in humans with type $2 \mathrm{DM}$ is not known. It has been found that immune cell infiltration of animal corneas may precede the induced hyperglycemia (ARVO 2015 e-abstract 3076). In fact, in a longitudinal rat study, the pre-diabetic obese rats have already manifested a similar amount of corneal nerve abnormalities with the diabetic rats. ${ }^{67}$ This suggests that accumulation of AGE, which is dependent on hyperglycemia and not present in pre-diabetic animals, is unlikely to be the cause of immune dysfunction in these animals. More animal studies with a mechanistic approach would be necessary to determine the cause of immune dysfunction in DM.

Do changes in corneal nerve structure lead to functional alteration? To answer this question the newer studies in Tables 1 and 2 also included corneal esthesiometry. This is a method of evaluation of corneal sensitivity which is a functional outcome of nerve innervation. These studies, except one, employed Cochrat Bonnet esthesiometry, which may not be as sensitive as a gas or Belmonte esthesiometry. Nevertheless, the studies were able to find an association between corneal nerve parameters and corneal sensitivity. ${ }^{6,46,49,75,76,79}$

It is also well known that apart from being neurotrophic, loss of corneal sensation also reduced lacrimal tear production since the corneal receptors are the afferent limb of the lacrimal reflex arc. ${ }^{3}$ The reduction of corneal innervation has been linked to abnormal tear function as well as more frequent and severe symptoms of dry eye in DM patients. ${ }^{9,21,27,43,83-86}$ These studies included those with or without previous surgical procedures such as LASIK and cataract surgeries. In one study, abnormal corneal innervation manifested as tear film dysfunction and debilitating, chronic irritation of the eye in type 1 but not in type $2 \mathrm{DM}^{43}$

\section{CORNEA STROMA AND BIOMECHANICS}

The corneal structure underneath the epithelium and the Bowman's layer is called the stroma. The corneal stroma is important because it accounts for $90 \%$ of the thickness of the cornea and therefore its tensile strength and biomechanical properties in general. ${ }^{87}$ The thickness of the human cornea is the most frequently measured parameter in clinical biometry of the eye. The main novelty in the recent clinical papers on corneal 
Table 2. Studies comparing corneal nerve parameters in different stages of diabetic peripheral neuropathy

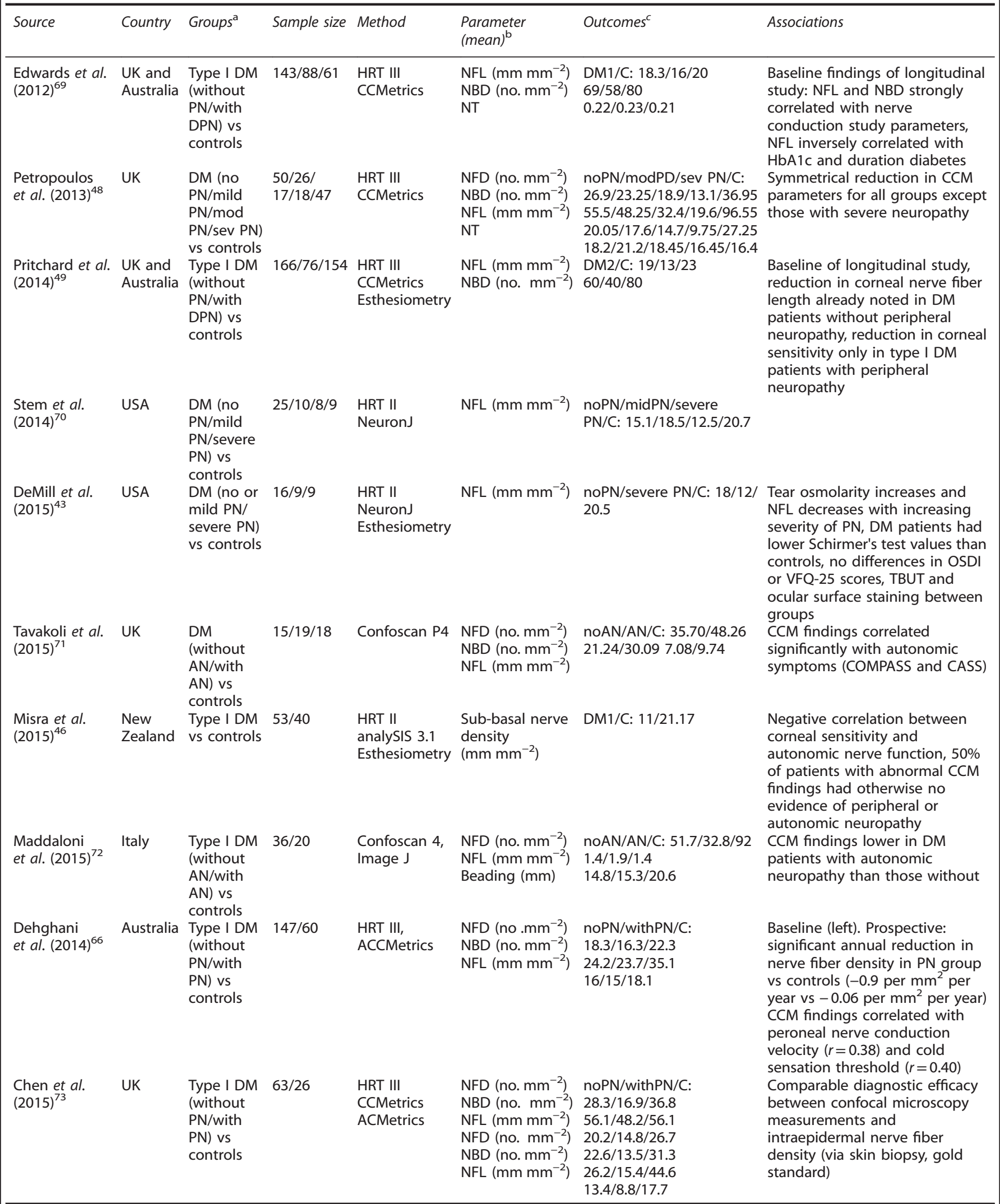

Abbreviations: ${ }^{\mathrm{a} A N}$, diabetic autonomic neuropathy; DM, diabetes mellitus; PN, diabetic peripheral neuropathy. ${ }^{\mathrm{b}} \mathrm{NBD}$, nerve branch density; NFD, nerve fiber density; NFL, nerve fiber length; NT, nerve tortuosity. ${ }^{\mathrm{C}} \mathrm{C}$, control; DM1, type 1 diabetes mellitus; DM2, type 2 diabetes melliltus. 
biomechanics involved the assessment of corneal hysteresis and resistance force, due to the recent availability of the Ocular Response Analyser, ${ }^{84,88,89}$ which can quantify these two parameters. Hysteresis refers to the amount of force required to indent the cornea as well as the recovery from the indentation. Resistance force is the hysteresis normalized to the cornea shape. A higher hysteresis suggests a more rigid and less deformable cornea. Seven cross-sectional clinic-based studies in Western Europe, ${ }^{87,90-92}$ United States, ${ }^{93}$ Brazil, $^{89}$ Israel $^{88}$ and Iran ${ }^{94}$ have found type 1 and type 2 DM participants to have higher hysteresis, whereas only one study (Turkish study) ${ }^{95}$ found them to have a lower hysteresis, compared with age-matched controls. In one study, it was found that the fasting blood glucose level was significantly but weakly correlated $(r=0.28)$ to the corneal hysteresis. $^{91}$

Two other studies published in this recent period on corneal morphology found DM to be associated with a greater corneal thickness, ${ }^{96-98}$ which was consistent with reports earlier than 2008. It is noteworthy that patients with proliferative, nonproliferative retinopathies and those with no diabetic retinopathies did not have significantly different corneal thicknesses. ${ }^{90,97-100}$ In addition, a study in 100 children aged 617 years with type $1 \mathrm{DM}$ in Romania had an increase in corneal thickness compared with an equivalent number of children of the same age, ${ }^{101}$ and similar findings had been reported in Turkey. ${ }^{96}$

The reason why DM is associated with greater corneal hysteresis or thicknesses is not completely known, apart from the relationship between increased corneal thicknesses in cases of overt corneal epitheliopathy. However, it has been speculated that the accumulation of AGE in the cornea stroma of diabetics may occur together with non-enzymatic crosslinking between collagen molecules and proteoglycans. The crosslinking would theoretically explain stiffening and thickening of the cornea. One study compared eight monkeys with insulin-dependent diabetes (streptozotocin injection) to four controls. In the diabetic eyes crosslinking has manifested ultra-structurally as abnormal collagen fibril aggregates in the stromal matrix on transmission electron microscopy. ${ }^{102}$ This is consistent with published evidence demonstrating AGE-induced crosslinking of extracellular matrix in diabetics, resulting in increased arterial stiffness. ${ }^{103}$ The fact that corneal thicknesses are elevated in children with DM who did not have other DM complications suggest that the cornea may be affected by AGE earlier than other organs. ${ }^{96,101}$ Nevertheless, it is premature at present to speculate if corneal pachymetry, commonly done in eye clinics, can be used to detect early DM changes.

Given that AGE-related crosslinking of corneal proteins can change the shape or morphology of the cornea in DM, is it possible that DM may influence specific eye disorders that manifests with corneal biomechanical changes? One such example is keratoconus, a degeneration of the cornea characterized by progressive ectasia or thinning of the cornea, typically presenting at teenage or early adult years. ${ }^{104}$ Unfortunately, the published cross-sectional studies did not demonstrate a consistent association between DM and such alteration of corneal shapes. $^{93,94}$

\section{CORNEA ENDOTHELIAL DISEASE}

Apart from the epithelium, the innermost layer of the cornea, called the corneal endothelium, plays a vital role in keeping the stroma dehydrated. This is because of the active pumping action of fluid from the cornea to the anterior chamber by the corneal endothelial cells. Similar types of regulated fluid transport are extremely important in diabetes in other contexts, for example, in the kidney.

Seven papers related to the corneal endothelium in DM have been published in the review period and all were hospital-based studies, except for one study comparing endothelial counts between diabetic and non-diabetic cadaveric donors. ${ }^{105-112}$ The biggest study of the 5, conducted in Vellor, India, involved 153 participants with DM and 163 age-matched controls, and was performed on patients before and after cataract surgery up to 3 months postoperatively. ${ }^{112}$ Preoperative examinations showed no statistically significant difference between the groups in any of the corneal endothelial parameters. Both DM and controls had decreases in endothelial counts and increase in morphological abnormalities (increase in cell sizes or polymegathism and increased variability of shape called pleomorphism) at 6 weeks and 3 months post-operation. The authors reported that in the control group the rate of loss of corneal endothelial cells between 6 weeks and 3 months was relatively milder compared with the DM group $(P=0.023)$. However, the actual measurements were not significantly different at any time points, suggesting that none of the differences discovered were clinically relevant. It is worth noting that this Indian study evaluated only small incision manual cataract surgery but did not investigate phacoemulsification; the latter is the more common form of surgery in the developed world and potentially induces more corneal endothelial cell loss than manual surgery. ${ }^{113}$

The other five papers were cross-sectional studies conducted in Korea, Malaysia and Hungary, Poland and Denmark. ${ }^{105-109}$ These studies excluded participants with prior cataract surgery or history of ocular disease, and reported statistically significant association of type $2 \mathrm{DM}$ with increased clinical features of corneal endothelial dysfunction (reduced endothelial count, and polymegathism and pleomorphism). Nevertheless, the magnitude of the reported differences between the DM and age-matched controls in these studies was very small. For example, in the Malaysian study, the mean corneal endothelial counts was 2541 cells per $\mathrm{mm}^{2}$ in DM compared with 2660 cells per $\mathrm{mm}^{2}$ in controls, with a difference of about 120 cells per $\mathrm{mm}^{2}$. By excluding participants with ophthalmic problems, these studies would have included only participants with shorter duration of DM. Had these studies recruited DM participants with longer durations, it may be possible to discover greater magnitudes of differences.

\section{ADVANCES IN TREATMENT OF DIABETIC OCULAR SURFACE}

Systemic treatment in DM is the cornerstone of treatment in any diabetic complication. Tight blood glucose control, preferably in collaboration with an endocrinologist, can prevent further progression of corneal epitheliopathy and neuropathy. ${ }^{63,114}$ Insulin treatment in diabetic mice reduced the level of oxidative stress in the lacrimal gland, assessed by total tissue peroxidase and malonaldehyde levels. ${ }^{83}$ The newer therapeutics approaches proposed in recent years and their limitations are summarized in Box 1.

The aim of local treatment in diabetic keratopathy is to maintain a smooth and lubricated ocular surface with an intact epithelium and adequate blink response. This minimizes visual distortion and maximizes comfort. The exact treatment prescribed is dependent on the severity of the problem and the specific structures involved. Early or mild disease will present as dry eye or recurrent erosions, and more severe disease in the form of neurotrophic ulcers and secondary infections. A step-wise approach towards treatment, such as that mentioned in the Dry Eye Workshop (DEWS), is helpful, aiming to halt further damage, encourage reepithelialization, prevent infection and maintain adequate lubrication of the ocular surface. ${ }^{2}$

A previous review has already described how therapies like lubricants, antibiotics, autologous serum and anti-inflammatory agents, as well as devices, such as bandage contact lenses in DM patients. ${ }^{2}$ The benefit of autologous serum is that it contains growth factors that may further enhance epithelial wound healing. An irregular ocular surface may benefit from a bandage contact 
Box 1 New systemic therapies

- Resolvin-D1, an anti-inflammatory eicosanoid, reduced corneal and peripheral nerve degeneration in diabetic rats when administered as an oral supplement together with menhaden (fish) oil. ${ }^{115}$ The effect was independent of blood glucose levels.

- Beta carotene, an antioxidant, was shown to ameliorate diabetes-related ultrastructural changes to the cornea in a rat model. $^{116}$ The beneficial effects of beta carotene was associated with a reduction in average blood glucose in treated groups.

- Ilepatril, a vasopeptidase inhibitor and new hypertension drug, can degrade vaso- and neuro-active petides as well as angiotension converting enzyme (ACE). In rats with streptozotocin-induced diabetes, oral administration of ilepatril protects against degeneration of the corneal nerves. ${ }^{117}$

- Enalapril, an ACE inhibitor, in combination with alpha lipoic acid (antioxidant) and menhaden oil was shown to reverse diabetic corneal and peripheral neuropathy in streptozotocin-induced diabetic rats when administrated per-orally. ${ }^{118}$

- KIOM-79 (a mixture of $80 \%$ ethanol extracts of parched Puerariae radix, gingered Magnoliae cortex, Glycyrrhizae radix and Euphorbiae radix) can be used as an oral therapeutic agent by reducing AGE in tissues like the cornea. In a rat model of DM, it also reduced the downstream oxidative damage, nuclear factor kappa-B activation and Bax overexpression in the cornea. ${ }^{119}$

- Experimental stem cell therapy, in the form of human hematopoietic stem cells transplanted into the peritoneum of rats, reduced apoptosis in the corneal and conjunctival epithelium. ${ }^{120}$ However, the corneal nerves were not examined in those experiments. It is important to note that such xenograft approaches also have to deal with the expected immune response against transplanted cells.

lens to reduce further trauma. For more severe conditions including neurotrophic ulcers, surgical options to induce eyelid closure, including botulinum toxin injection and tarsorrhaphy, may be required.

Some of the newer treatment modalities directed to the ocular surface have been recently reviewed are summarized in Box 2 . The challenge of maintaining therapeutic concentrations of any topical drugs on the ocular surface is the rapid dilution by resident tears and elimination through the nasolacrimal duct.

\section{CONCLUSION AND FUTURE STUDIES}

The assessment of the diabetic ocular surface has implications beyond eye care. Challenges and future directions in this field are described in the Boxes 1 and 2. The corneal nerve parameters are all age related and, therefore, widespread use of these features for screening patients will only be useful if age-stratified normative values are available for the target population. ${ }^{17}$ Reading centers for corneal imaging will play a major role in such initiatives. Use of special imaging techniques such as 2-photon microscopy in genetically modified mice with visible corneal nerves will be immensely valuable to investigate changes in animals with diabetic neuropathy, especially in the cornea. ${ }^{7}$

Apart from more conventional approaches, newer therapeutic agents including targeted molecular therapy, gene and stem cell
Box 2 New topical therapies in diabetic ocular surface

- Carnosine, an antioxidant, may be used to counter the effects of AGE in the ocular surface. ${ }^{115}$ Topical administration of the substance has been shown to be effective in maintaining thiol levels in the cornea of rats with induced diabetes. This study unfortunately did not included assessment of the tear function and health of the ocular surface by imaging. ${ }^{121}$

- Sericin and aloe vera are topical protective agents and promote ocular surface wound healing. ${ }^{122,123}$

- Naltrexone, a long-acting opioid antagonist, administrated topically or orally has been shown to accelerate corneal wound healing and restitute corneal sensitivity. It has also been shown to be safe and effective in more than one type of animal model. $12,85,86,124,125$

- Topical application of growth factors in diabetic animal models, in particular insulin and nerve growth factor (NGF), have had promising results. ${ }^{81,124}$ Insulin is a much cheaper drug to produce than NGF, and therefore more likely to widely adopted, but it does not protect against the loss of corneal sensitivity. Moreover NGF can be easily degraded by alteration of temperature, $\mathrm{pH}$ and presence of tear proteases. ${ }^{126}$

- Insulin-like growth factor 1 (IGF-1) promotes cell proliferation and when administrated topically to type 2 diabetic mice. Improved corneal sub-basal nerve density compared with controls. $^{127}$

- Targeting microRNA miR-146Aa may be used to treat delays in wound healing in diabetic corneas, but this had been reported in organ cultures only. ${ }^{128}$

- Experimental gene therapies may be a viable form of local treatment for cornea disease in diabetics. Hepatic growth factor (HGF)-driven epithelial migration and wound closure is dependent on the function of the receptor tyrosine kinase c-Met. In DM animal models, the HGF levels were increased in the cornea epithelium, but the c-Met levels have decreased. Since inadequate c-Met levels may impair wound healing, adenoviral vector mediated overexpression of c-Met was attempted to correct the molecular anomaly. In organcultured human corneas from diabetic patients, the rate of epithelial migration was restored to the levels in the nondiabetic corneas. Though promising, such therapies have numerous hurdles to overcome, including safety concerns and issues related to the lack of specificity in delivery of expression vectors. ${ }^{129-131}$

therapies are promising but have not yet been translated to routine care. The bulk of the published work in these areas concerns evaluation in animal models and not clinical trials.

The future of diabetes management is dependent on increased awareness of the importance of the ocular surface in diabetes. An improved understanding of the ocular surface among the general medical profession is essential for optimal management.

\section{CONFLICT OF INTEREST}

The authors declare no conflict of interest.

\section{ACKNOWLEDGEMENTS}

We would thank the Singapore Eye Research Institute and the University of Hong Kong for making this collaborative effort possible. 


\section{REFERENCES}

1 Alves Mde C, Carvalheira JB, Modulo CM, Rocha EM. Tear film and ocular surface changes in diabetes mellitus. Arq Bras Oftalmol 2008; 71: 96-103.

2 Abdelkader H, Patel DV, McGhee C, Alany RG. New therapeutic approaches in the treatment of diabetic keratopathy: a review. Clin Exp Ophthalmol 2011; 39: 259-270.

3 Bikbova G, Oshitari T, Tawada A, Yamamoto S. Corneal changes in diabetes mellitus. Curr Diabetes Rev 2012; 8: 294-302.

4 Calvo-Maroto AM, Perez-Cambrodi RJ, Albaran-Diego C, Pons A, Cervino A. Optical quality of the diabetic eye: a review. Eye (London, England) 2014; 28: 1271-1280.

5 De Clerck EE, Schouten JS, Berendschot TT, Kessels AG, Nuijts RM, Beckers HJ et al. New ophthalmologic imaging techniques for detection and monitoring of neurodegenerative changes in diabetes: a systematic review. Lancet Diabetes Endocrinol 2015; 3: 653-663.

6 Efron N. The Glenn A. Fry award lecture 2010: Ophthalmic markers of diabetic neuropathy. Optometry Vis Sci 2011; 88: 661-683.

7 Ehmke T, Leckelt J, Reichard M, Weiss H, Hovakimyan M, Heisterkamp A et al. In vivo nonlinear imaging of corneal structures with special focus on BALB/c and streptozotocin-diabetic Thy1-YFP mice. Exp Eye Res 2015; 146: 137-144.

8 Lutty GA. Effects of diabetes on the eye. Invest Ophthalmol Vis Sci 2013; 54: Orsf81-Orsf87.

9 Lv H, Li A, Zhang X, Xu M, Qiao Y, Zhang J et al. Meta-analysis and review on the changes of tear function and corneal sensitivity in diabetic patients. Acta Ophthalmol 2014; 92: e96-e104.

10 Malik RA. Which test for diagnosing early human diabetic neuropathy? Diabetes 2014; 63: 2206-2208.

11 Malik RA. From the bedside to the bench and back again, with corneal confocal microscopy. Invest Ophthalmol Vis Sci 2014; 55: 1231.

12 McLaughlin PJ, Sassani JW, Klocek MS, Zagon IS. Diabetic keratopathy and treatment by modulation of the opioid growth factor (OGF)-OGF receptor (OGFr) axis with naltrexone: a review. Brain Res Bull 2010; 81: 236-247.

13 Patel DV, McGhee CN. Techniques for wide-field assessment of the human corneal subbasal nerve plexus. Cornea 2013; 32: e140-e141.

14 Patel SV. Corneal confocal microscopy and diabetic neuropathy. Invest Ophthalmol Vis Sci 2015; 56: 5066.

15 Shtein RM, Callaghan BC. Corneal confocal microscopy as a measure of diabetic neuropathy. Diabetes 2013; 62: 25-26.

16 Surnina ZV. [Opportunities for confocal and laser biomicroscopy of corneal nerves in diabetic polyneuropathy]. Vestnik oftalmologii 2015; 131: 104-108.

17 Tavakoli M, Petropoulos IN, Malik RA. Corneal confocal microscopy to assess diabetic neuropathy: an eye on the foot. J Diabetes Sci Technol 2013; 7: 1179-1189.

18 Vislisel JM, Liaboe CA, Wagoner MD, Goins KM, Sutphin JE, Schmidt GA et al. Graft survival of diabetic versus nondiabetic donor tissue after initial keratoplasty. Cornea 2015; 34: 370-374.

19 Wang H, Fan D, Zhang S, Wang X. [Early diagnosis of painful diabetic neuropathy by corneal confocal microscopy]. Zhonghua yi xue za zhi 2014; 94: 2602-2606.

$20 \mathrm{Ye} \mathrm{H}$, Lu Y. Corneal bullous epithelial detachment in diabetic cataract surgery. Optometry Vis Sci 2015; 92: e161-e164.

21 Achtsidis V, Eleftheriadou I, Kozanidou E, Voumvourakis Kl, Stamboulis E, Theodosiadis PG et al. Dry eye syndrome in subjects with diabetes and association with neuropathy. Diabetes Care 2014; 37: e210-e211.

22 Nagai N, Murao T, Okamoto N, Ito Y. Kinetic analysis of the rate of corneal wound healing in Otsuka long-evans Tokushima Fatty rats, a model of type 2 diabetes mellitus. J Oleo Sci 2010; 59: 441-449.

$23 \mathrm{Xu} \mathrm{KP,} \mathrm{Li} \mathrm{Y,} \mathrm{Ljubimov} \mathrm{AV,} \mathrm{Yu} \mathrm{FS.} \mathrm{High} \mathrm{glucose} \mathrm{suppresses} \mathrm{epidermal} \mathrm{growth}$ factor receptor/phosphatidylinositol 3-kinase/Akt signaling pathway and attenuates corneal epithelial wound healing. Diabetes 2009; 58: 1077-1085.

24 Latour G, Kowalczuk L, Savoldelli M, Bourges JL, Plamann K, Behar-Cohen F et al. Hyperglycemia-induced abnormalities in rat and human corneas: the potential of second harmonic generation microscopy. PLOS ONE 2012; 7: e48388.

25 Funari VA, Winkler M, Brown J, Dimitrijevich SD, Ljubimov AV, Saghizadeh M. Differentially expressed wound healing-related microRNAs in the human diabetic cornea. PLOS ONE 2013; 8: e84425.

26 Wu YC, Buckner BR, Zhu M, Cavanagh HD, Robertson DM. Elevated IGFBP3 levels in diabetic tears: a negative regulator of IGF-1 signaling in the corneal epithelium. Ocul Surf 2012; 10: 100-107.

27 Liu H, Sheng M, Liu Y, Wang P, Chen Y, Chen L et al. Expression of SIRT1 and oxidative stress in diabetic dry eye. Int J Clin Exp Pathol 2015; 8: 7644-7653.

28 Zhou Q, Chen P, Di G, Zhang Y, Wang Y, Qi X et al. Ciliary neurotrophic factor promotes the activation of corneal epithelial stem/progenitor cells and accelerates corneal epithelial wound healing. Stem Cells 2015; 33: 1566-1576.

29 Kim EC, Kim DJ, Lee SS, Kim MS. Ultrastructural changes of cornea after ethanol ingestion in Otsuka Long-Evans Tokushima fatty (OLETF) and Long-Evans
Tokushima Otsuka (LETO) rats. Graef Arch Clin Exp Ophthalmol=Albrecht von Graef Arch Klin Exp Ophthalmol 2010; 248: 1457-1466.

30 Kim J, Kim CS, Sohn E, Jeong IH, Kim H, Kim JS. Involvement of advanced glycation end products, oxidative stress and nuclear factor-kappaB in the development of diabetic keratopathy. Graef Arch Clin Exp Ophthalmol=Albrecht von Graef Arch Klin Exp Ophthalmol 2011; 249: 529-536.

31 Yin J, Huang J, Chen C, Gao N, Wang F, Yu FS. Corneal complications in streptozocin-induced type I diabetic rats. Invest Ophthalmol Vis Sci 2011; 52: 6589-6596.

32 Adnan, Atchison DA. Changes in straylight and corneal light scattering in a newly diagnosed case of type 2 diabetes. Clin Exp Optometry 2015; 98: 481-482.

33 Burnham JM, Sakhalkar M, Langford MP, Liang C, Redens TB, Jain SK. Diabetic and non-diabetic human cornea and tear gamma-glutamyl transpeptidase activity. Clin Ophthalmol 2013; 7: 99-107.

34 Akhtar S, Almubrad T, Bron AJ, Yousif MH, Benter IF, Akhtar S. Role of epidermal growth factor receptor (EGFR) in corneal remodelling in diabetes. Acta Ophthalmol 2009; 87: 881-889.

35 Bettahi I, Sun H, Gao N, Wang F, Mi X, Chen W et al. Genome-wide transcriptional analysis of differentially expressed genes in diabetic, healing corneal epithelial cells: hyperglycemia-suppressed TGFbeta3 expression contributes to the delay of epithelial wound healing in diabetic corneas. Diabetes 2014; 63: 715-727.

36 Lan W, Petznick A, Heryati S, Rifada M, Tong L. Nuclear factor-kappaB: central regulator in ocular surface inflammation and diseases. Ocul Surf 2012; 10: 137-148.

37 Byun YS, Kang B, Yoo YS, Joo CK. Poly(ADP-Ribose) polymerase inhibition improves corneal epithelial innervation and wound healing in diabetic rats. Invest Ophthalmol Vis Sci 2015; 56: 1948-1955.

38 Yang L, Di G, Qi X, Qu M, Wang Y, Duan H et al. Substance P promotes diabetic corneal epithelial wound healing through molecular mechanisms mediated via the neurokinin-1 receptor. Diabetes 2014; 63: 4262-4274.

39 Davidson EP, Coppey LJ, Holmes A, Yorek MA. Changes in corneal innervation and sensitivity and acetylcholine-mediated vascular relaxation of the posterior ciliary artery in a type 2 diabetic rat. Invest Ophthalmol Vis Sci 2012; 53: 1182-1187.

$40 \mathrm{He} \mathrm{J,} \mathrm{Bazan} \mathrm{HE.} \mathrm{Mapping} \mathrm{the} \mathrm{nerve} \mathrm{architecture} \mathrm{of} \mathrm{diabetic} \mathrm{human} \mathrm{corneas.}$ Ophthalmology 2012; 119: 956-964.

41 Avetisov SE, Novikov IA, Makhotin SS, Surnina ZV. [New approach to corneal nerve fibers morphometry in diabetes mellitus on the basis of confocal biomicroscopy]. Vestnik oftalmologii 2015; 131: 5-14.

42 Edwards K, Pritchard N, Vagenas D, Russell A, Malik RA, Efron N. Standardizing corneal nerve fibre length for nerve tortuosity increases its association with measures of diabetic neuropathy. Diabet Med 2014; 31: 1205-1209.

43 DeMill DL, Hussain M, Pop-Busui R, Shtein RM. Ocular surface disease in patients with diabetic peripheral neuropathy. Br J Ophthalmol 2016; 100: 7924-7928.

44 Pritchard N, Edwards K, Russell AW, Perkins BA, Malik RA, Efron N. Corneal confocal microscopy predicts 4-year incident peripheral neuropathy in type 1 diabetes. Diabetes Care 2015; 38: 671-675.

45 Messmer EM, Schmid-Tannwald C, Zapp D, Kampik A. In vivo confocal microscopy of corneal small fiber damage in diabetes mellitus. Graef Arch Clin Exp Ophthalmol = Albrecht von Graef Arch Klin Exp Ophthalmol 2010; 248: 1307-1312.

46 Misra SL, Craig JP, Patel DV, McGhee CN, Pradhan M, Ellyett $\mathrm{K}$ et al. In vivo confocal microscopy of corneal nerves: an ocular biomarker for peripheral and cardiac autonomic neuropathy in type 1 diabetes mellitus. Invest Ophthalmol Vis Sci 2015; 56: 5060-5065.

47 Nitoda E, Kallinikos P, Pallikaris A, Moschandrea J, Amoiridis G, Ganotakis ES et al. Correlation of diabetic retinopathy and corneal neuropathy using confocal microscopy. Curr Eye Res 2012; 37: 898-906.

48 Petropoulos IN, Alam U, Fadavi H, Asghar O, Green P, Ponirakis G et al. Corneal nerve loss detected with corneal confocal microscopy is symmetrical and related to the severity of diabetic polyneuropathy. Diabetes Care 2013; 36: 3646-3651.

49 Pritchard N, Edwards K, Dehghani C, Fadavi H, Jeziorska M, Marshall A et al. Longitudinal assessment of neuropathy in type 1 diabetes using novel ophthalmic markers (LANDMark): study design and baseline characteristics. Diabetes Res Clin Pract 2014; 104: 248-256.

50 Pritchard N, Dehghani C, Edwards K, Burgin E, Cheang N, Kim H et al. Utility of assessing nerve morphology in central cornea versus whorl area for diagnosing diabetic peripheral neuropathy. Cornea 2015; 34: 756-761.

51 Petropoulos IN, Ferdousi M, Marshall A, Alam U, Ponirakis G, Azmi S et al. The inferior whorl for detecting diabetic peripheral neuropathy using corneal confocal microscopy. Invest Ophthalmol Vis Sci 2015; 56: 2498-2504.

52 Dabbah MA, Graham J, Petropoulos IN, Tavakoli M, Malik RA. Automatic analysis of diabetic peripheral neuropathy using multi-scale quantitative morphology of nerve fibres in corneal confocal microscopy imaging. Med Image Anal 2011; 15: 738-747 
53 Zhivov A, Winter K, Peschel S, Guthoff RF, Stachs O, Harder V et al. [Quantitative analysis of corneal subbasal nerve plexus with in vivo confocal laser scanning microscopy]. Klin Monbl Augenheilkund 2011; 228: 1067-1072.

54 Efron N, Edwards K, Roper N, Pritchard N, Sampson GP, Shahidi AM et al. Repeatability of measuring corneal subbasal nerve fiber length in individuals with type 2 diabetes. Eye Contact Lens 2010; 36: 245-248.

55 Hume DA, Lovblom LE, Ahmed A, Yeung E, Orszag A, Shin TM et al. Higher magnification lenses versus conventional lenses for evaluation of diabetic neuropathy by corneal in vivo confocal microscopy. Diabetes Res Clin Pract 2012; 97: e37-e40.

56 Petropoulos IN, Alam U, Fadavi H, Marshall A, Asghar O, Dabbah MA et al. Rapid automated diagnosis of diabetic peripheral neuropathy with in vivo corneal confocal microscopy. Invest Ophthalmol Vis Sci 2014; 55: 2071-2078.

57 Ahmed A, Bril V, Orszag A, Paulson J, Yeung E, Ngo M et al. Detection of diabetic sensorimotor polyneuropathy by corneal confocal microscopy in type 1 diabetes: a concurrent validity study. Diabetes Care 2012; 35: 821-828.

58 Hertz P, Bril V, Orszag A, Ahmed A, Ng E, Nwe P et al. Reproducibility of in vivo corneal confocal microscopy as a novel screening test for early diabetic sensorimotor polyneuropathy. Diabetic Med 2011; 28: 1253-1260.

59 Sellers EA, Clark I, Tavakoli M, Dean HJ, McGavock J, Malik RA. The acceptability and feasibility of corneal confocal microscopy to detect early diabetic neuropathy in children: a pilot study. Diabet Med 2013; 30: 630-631.

60 Utsunomiya T, Nagaoka T, Hanada K, Omae T, Yokota H, Abiko A et al. Imaging of the corneal subbasal whorl-like nerve plexus: more accurate depiction of the extent of corneal nerve damage in patients with diabetes. Invest Ophthalmol Vis Sci 2015; 56: 5417-5423.

61 Dehghani C, Pritchard N, Edwards K, Russell AW, Malik RA, Efron N. Fully automated, semiautomated, and manual morphometric analysis of corneal subbasal nerve plexus in individuals with and without diabetes. Cornea 2014; 33: 696-702.

62 Edwards K, Pritchard N, Gosschalk K, Sampson GP, Russell A, Malik RA et al. Widefield assessment of the human corneal subbasal nerve plexus in diabetic neuropathy using a novel mapping technique. Cornea 2012; 31: 1078-1082.

63 Ishibashi F, Okino M, Ishibashi M, Kawasaki A, Endo N, Kosaka A et al. Corneal nerve fiber pathology in Japanese type 1 diabetic patients and its correlation with antecedent glycemic control and blood pressure. J Diabetes Invest 2012; 3: 191-198.

64 Zhivov A, Winter K, Hovakimyan M, Peschel S, Harder V, Schober HC et al. Imaging and quantification of subbasal nerve plexus in healthy volunteers and diabetic patients with or without retinopathy. PLOS ONE 2013; 8: e52157.

65 Ziegler D, Papanas N, Zhivov A, Allgeier S, Winter K, Ziegler I et al. Early detection of nerve fiber loss by corneal confocal microscopy and skin biopsy in recently diagnosed type 2 diabetes. Diabetes 2014; 63: 2454-2463.

66 Dehghani C, Pritchard N, Edwards K, Vagenas D, Russell AW, Malik RA et al. Natural history of corneal nerve morphology in mild neuropathy associated with type 1 diabetes: development of a potential measure of diabetic peripheral neuropathy. Invest Ophthalmol Vis Sci 2014; 55: 7982-7990.

67 Yorek MS, Obrosov A, Shevalye H, Lupachyk S, Harper MM, Kardon RH et al. Effect of glycemic control on corneal nerves and peripheral neuropathy in streptozotocin-induced diabetic C57BI/6 J mice. J Peripher Nerv System 2014; 19: 205-217.

68 Yorek MS, Obrosov A, Shevalye H, Holmes A, Harper MM, Kardon RH et al. Effect of diet-induced obesity or type 1 or type 2 diabetes on corneal nerves and peripheral neuropathy in C57BI/6 J mice. J Peripher Nerv System 2015; 20: 24-31.

69 Edwards K, Pritchard N, Vagenas D, Russell A, Malik RA, Efron N. Utility of corneal confocal microscopy for assessing mild diabetic neuropathy: baseline findings of the LANDMark study. Clin Exp Optometry 2012; 95: 348-354.

70 Stem MS, Hussain M, Lentz SI, Raval N, Gardner TW, Pop-Busui R et al. Differential reduction in corneal nerve fiber length in patients with type 1 or type 2 diabetes mellitus. J Diabetes Complications 2014; 28: 658-661.

71 Tavakoli M, Begum P, McLaughlin J, Malik RA. Corneal confocal microscopy for the diagnosis of diabetic autonomic neuropathy. Muscle Nerve 2015; 52: 363-370.

72 Maddaloni E, Sabatino F, Del Toro R, Crugliano S, Grande S, Lauria Pantano A et al. In vivo corneal confocal microscopy as a novel non-invasive tool to investigate cardiac autonomic neuropathy in type 1 diabetes. Diabetic Med 2015; 32: $262-266$

73 Chen X, Graham J, Dabbah MA, Petropoulos IN, Ponirakis G, Asghar O et al. Small nerve fiber quantification in the diagnosis of diabetic sensorimotor polyneuropathy: comparing corneal confocal microscopy with intraepidermal nerve fiber density. Diabetes Care 2015; 38: 1138-1144.

74 Breiner A, Lovblom LE, Perkins BA, Bril V. Does the prevailing hypothesis that small-fiber dysfunction precedes large-fiber dysfunction apply to type 1 diabetic patients? Diabetes Care 2014; 37: 1418-1424.
75 Pritchard N, Edwards K, Vagenas D, Russell AW, Malik RA, Efron N. Corneal sensitivity is related to established measures of diabetic peripheral neuropathy. Clin Exp Optometry 2012; 95: 355-361.

76 Pritchard N, Edwards K, Vagenas D, Shahidi AM, Sampson GP, Russell AW et al. Corneal sensitivity as an ophthalmic marker of diabetic neuropathy. Optometry Vis Sci 2010; 87: 1003-1008.

77 Sivaskandarajah GA, Halpern EM, Lovblom LE, Weisman A, Orlov S, Bril V et al. Structure-function relationship between corneal nerves and conventional smallfiber tests in type 1 diabetes. Diabetes Care 2013; 36: 2748-2755.

78 Bitirgen G, Ozkagnici A, Malik RA, Kerimoglu H. Corneal nerve fibre damage precedes diabetic retinopathy in patients with type 2 diabetes mellitus. Diabetic Med 2014; 31: 431-438.

79 Tavakoli M, Boulton AJ, Efron N, Malik RA. Increased Langerhan cell density and corneal nerve damage in diabetic patients: role of immune mechanisms in human diabetic neuropathy. Cont Lens Anterior Eye 2011; 34: 7-11.

80 Leppin K, Behrendt AK, Reichard M, Stachs O, Guthoff RF, Baltrusch S et al. Diabetes mellitus leads to accumulation of dendritic cells and nerve fiber damage of the subbasal nerve plexus in the cornea. Invest Ophthalmol Vis Sci 2014; 55: 3603-3615.

81 Kim HC, Cho YJ, Ahn CW, Park KS, Kim JC, Nam JS et al. Nerve growth factor and expression of its receptors in patients with diabetic neuropathy. Diabetic Med 2009; 26: 1228-1234.

82 Priyadarsini S, Sarker-Nag A, Allegood J, Chalfant C, Karamichos D. Description of the sphingolipid content and subspecies in the diabetic cornea. Current Eye Res 2015; 40: 1204-1210.

83 Modulo CM, Jorge AG, Dias AC, Braz AM, Bertazolli-Filho R, Jordao AA Jr et al. Influence of insulin treatment on the lacrimal gland and ocular surface of diabetic rats. Endocrine 2009; 36: 161-168.

84 Oriowo OM. Profile of central corneal thickness in diabetics with and without dry eye in a Saudi population. Optometry (St Louis, MO) 2009; 80: 442-446.

85 Zagon IS, Klocek MS, Sassani JW, McLaughlin PJ. Dry eye reversal and corneal sensation restoration with topical naltrexone in diabetes mellitus. Arch Ophthalmol 2009; 127: 1468-1473.

86 Zagon IS, Sassani JW, Immonen JA, McLaughlin PJ. Ocular surface abnormalities related to type 2 diabetes are reversed by the opioid antagonist naltrexone. Clin Exp Ophthalmol 2014; 42: 159-168.

87 Hager A, Wegscheider K, Wiegand W. Changes of extracellular matrix of the cornea in diabetes mellitus. Graef Arch Clin Exp Ophthalmol=Albrecht von Graef Arch Klin Exp Ophthalmol 2009; 247: 1369-1374.

88 Goldich Y, Barkana Y, Gerber Y, Rasko A, Morad Y, Harstein M et al. Effect of diabetes mellitus on biomechanical parameters of the cornea. $J$ Cataract Refract Surg 2009; 35: 715-719.

89 Castro DP, Prata TS, Lima VC, Biteli LG, de Moraes CG, Paranhos A Jr. Corneal viscoelasticity differences between diabetic and nondiabetic glaucomatous patients. J Glaucoma 2010; 19: 341-343.

90 Perez-Rico C, Gutierrez-Ortiz C, Gonzalez-Mesa A, Zandueta AM, MorenoSalqueiro A, Germain F. Effect of diabetes mellitus on Corvis ST measurement process. Acta Ophthalmol 2015; 93: e193-e198.

91 Kotecha A, Oddone F, Sinapis C, Elsheikh A, Sinapis D, Sinapis A et al. Corneal biomechanical characteristics in patients with diabetes mellitus. J Cataract Refract Surg 2010; 36: 1822-1828.

92 Scheler A, Spoerl E, Boehm AG. Effect of diabetes mellitus on corneal biomechanics and measurement of intraocular pressure. Acta Ophthalmol 2012; 90: e447-e451.

93 Kosker M, Suri K, Hammersmith KM, Nassef AH, Nagra PK, Rapuano CJ. Another look at the association between diabetes and keratoconus. Cornea 2014; 33: 774-779.

94 Naderan M, Naderan M, Rezagholizadeh F, Zolfaghari M, Pahlevani R, Rajabi MT. Association between diabetes and keratoconus: a case-control study. Cornea 2014; 33: 1271-1273

95 Sahin A, Bayer A, Ozge G, Mumcuoglu T. Corneal biomechanical changes in diabetes mellitus and their influence on intraocular pressure measurements. Invest Ophthalmol Vis Sci 2009; 50: 4597-4604.

96 Akinci A, Bulus D, Aycan Z, Oner O. Central corneal thickness in children with diabetes. J Refract Surg 2009; 25: 1041-1044.

97 Toygar O, Sizmaz S, Pelit A, Toygar B, Yabas Kiziloglu O, Akova Y. Central corneal thickness in type II diabetes mellitus: is it related to the severity of diabetic retinopathy? Turkish J Med Sci 2015; 45: 651-654.

98 Ozdamar Y, Cankaya B, Ozalp S, Acaroglu G, Karakaya J, Ozkan SS. Is there a correlation between diabetes mellitus and central corneal thickness? J Glaucoma 2010; 19: 613-616.

99 Ni S, Yu J, Bao F, Li J, Elsheikh A, Wang Q. Effect of glucose on the stress-strain behavior of ex-vivo rabbit cornea. Exp Eye Res 2011; 92: 353-360. 
100 Nishitsuka K, Kawasaki R, Kanno M, Tanabe Y, Saito K, Honma K et al. Determinants and risk factors for central corneal thickness in Japanese persons: the Funagata Study. Ophthalmic Epidemiol 2011; 18: 244-249.

101 Tiutiuca C. [Assessment of central corneal thickness in children with diabetus mellitus type I]. Oftalmologia 2013; 57: 26-32.

102 Zou C, Wang S, Huang F, Zhang YA. Advanced glycation end products and ultrastructural changes in corneas of long-term streptozotocin-induced diabetic monkeys. Cornea 2012; 31: 1455-1459.

103 Goldin A, Beckman JA, Schmidt AM, Creager MA. Advanced glycation end products: sparking the development of diabetic vascular injury. Circulation 2006; 114: 597-605

104 Patel DV, Ku JY, Johnson R, McGhee CN. Laser scanning in vivo confocal microscopy and quantitative aesthesiometry reveal decreased corneal innervation and sensation in keratoconus. Eye (Lond) 2009; 23: 586-592.

105 Choo M, Prakash K, Samsudin A, Soong T, Ramli N, Kadir A. Corneal changes in type II diabetes mellitus in Malaysia. Int J Ophthalmol 2010; 3: 234-236.

106 Leem HS, Lee KJ, Shin KC. Central corneal thickness and corneal endothelial cell changes caused by contact lens use in diabetic patients. Yonsei Med J 2011; 52: 322-325.

107 Storr-Paulsen A, Singh A, Jeppesen H, Norregaard JC, Thulesen J. Corneal endothelial morphology and central thickness in patients with type II diabetes mellitus. Acta Ophthalmol 2014; 92: 158-160.

108 Modis L Jr, Szalai E, Kertesz K, Kemeny-Beke A, Kettesy B, Berta A. Evaluation of the corneal endothelium in patients with diabetes mellitus type I and II. Histol Histopathol 2010; 25: 1531-1537.

109 Urban B, Raczynska D, Bakunowicz-Lazarczyk A, Raczynska K, Kretowska M. Evaluation of corneal endothelium in children and adolescents with type 1 diabetes mellitus. Mediators Inflamm 2013; 2013: 913754.

110 Misra SL, Goh YW, Patel DV, Riley AF, McGhee CN. Corneal microstructural changes in nerve fiber, endothelial and epithelial density after cataract surgery in patients with diabetes mellitus. Cornea 2015; 34: 177-181.

111 Lass JH, Riddlesworth TD, Gal RL, Kollman C, Benetz BA, Price FW Jr et al. The effect of donor diabetes history on graft failure and endothelial cell density 10 years after penetrating keratoplasty. Ophthalmology 2015; 122: 448-456.

112 Mathew PT, David S, Thomas N. Endothelial cell loss and central corneal thickness in patients with and without diabetes after manual small incision cataract surgery. Cornea 2011; 30: 424-428.

113 Dhasmana R, Singh IP, Nagpal RC. Corneal changes in diabetic patients after manual small incision cataract surgery. J Clin Diagn Res 2014; 8: Vc03-Vc06.

114 Tavakoli M, Kallinikos P, lqbal A, Herbert A, Fadavi H, Efron N et al. Corneal confocal microscopy detects improvement in corneal nerve morphology with an improvement in risk factors for diabetic neuropathy. Diabetic Med 2011; 28: 1261-1267.

115 Shevalye H, Yorek MS, Coppey L, Holmes A, Harper MM, Kardon RH et al. Effect of enriching the diet with menhaden oil or daily treatment with resolvin D1 on neuropathy in a mouse model of type 2 diabetes. J Neurophysiol 2015; 114: 199-208.

116 Abdul-Hamid M, Moustafa N. Amelioration of alloxan-induced diabetic keratopathy by beta-carotene. Exp Toxicol Pathol 2014; 66: 49-59.

117 Davidson EP, Coppey $\sqcup$, Yorek MA. Early loss of innervation of cornea epithelium in streptozotocin-induced type 1 diabetic rats: improvement with ilepatril treatment. Invest Ophthalmol Vis Sci 2012; 53: 8067-8074.

118 Davidson EP, Holmes A, Coppey LJ, Yorek MA. Effect of combination therapy consisting of enalapril, alpha-lipoic acid, and menhaden oil on diabetic neuropathy in a high fat/low dose streptozotocin treated rat. Eur J Pharmacol 2015; 765: 258-267.

119 Kim J, Kim CS, Kim H, Jeong IH, Sohn E, Kim JS. Protection against advanced glycation end products and oxidative stress during the development of diabetic keratopathy by KIOM-79. J Pharmacy Pharmacol 2011; 63: 524-530.

120 Zickri MB, Ahmad NA, Maadawi ZM, Mohamady YK, Metwally HG. Effect of stem cell therapy on induced diabetic keratopathy in albino rat. Int J Stem Cells 2012; 5: 57-64.

121 Shi Q, Yan H. Changes of the thiol levels in the corneas of the diabetic rats: effect of carnosine, aspirin and a combination eye drops. Int J Ophthalmol 2010; 3: 211-215.

122 Nagai N, Ito Y. Therapeutic effects of sericin on diabetic keratopathy in Otsuka Long-Evans Tokushima Fatty rats. World J Diabetes 2013; 4: 282-289.

123 Atiba A, Wasfy T, Abdo W, Ghoneim A, Kamal T, Shukry M. Aloe vera gel facilitates re-epithelialization of corneal alkali burn in normal and diabetic rats. Clin Ophthalmol 2015; 9: 2019-2026.

124 Klocek MS, Sassani JW, McLaughlin PJ, Zagon IS. Naltrexone and insulin are independently effective but not additive in accelerating corneal epithelial healing in type I diabetic rats. Exp Eye Res 2009; 89: 686-692.

125 Zagon IS, Sassani JW, Carroll MA, McLaughlin PJ. Topical application of naltrexone facilitates reepithelialization of the cornea in diabetic rabbits. Brain Res Bull 2010; 81: 248-255.

126 Chen DK, Frizzi KE, Guernsey LS, Ladt K, Mizisin AP, Calcutt NA. Repeated monitoring of corneal nerves by confocal microscopy as an index of peripheral neuropathy in type- 1 diabetic rodents and the effects of topical insulin. J Peripher Nerv System 2013; 18: 306-315.

127 Ueno H, Hattori T, Kumagai Y, Suzuki N, Ueno S, Takagi H. Alterations in the corneal nerve and stem/progenitor cells in diabetes: preventive effects of insulin-like growth factor-1 treatment. Int J Endocrinol 2014; 2014: 312401.

128 Winkler MA, Dib C, Ljubimov AV, Saghizadeh M. Targeting miR-146a to treat delayed wound healing in human diabetic organ-cultured corneas. PLOS ONE 2014; 9: e114692.

129 Saghizadeh M, Kramerov AA, Yu FS, Castro MG, Ljubimov AV. Normalization of wound healing and diabetic markers in organ cultured human diabetic corneas by adenoviral delivery of c-Met gene. Invest Ophthalmol Vis Sci 2010; 51: 1970-1980.

130 Saghizadeh M, Dib CM, Brunken WJ, Ljubimov AV. Normalization of wound healing and stem cell marker patterns in organ-cultured human diabetic corneas by gene therapy of limbal cells. Exp Eye Res 2014; 129: 66-73.

131 Saghizadeh M, Epifantseva I, Hemmati DM, Ghiam CA, Brunken WJ, Ljubimov AV. Enhanced wound healing, kinase and stem cell marker expression in diabetic organ-cultured human corneas upon MMP-10 and cathepsin F gene silencing. Int J Endocrinol 2013; 54: 8172-8180.

(i) This work is licensed under a Creative Commons Attribution 4.0 International License. The images or other third party material in this article are included in the article's Creative Commons license, unless indicated otherwise in the credit line; if the material is not included under the Creative Commons license, users will need to obtain permission from the license holder to reproduce the material. To view a copy of this license, visit http://creativecommons.org/licenses/ by/4.0/

(c) The Author(s) 2017 